\title{
Comparison of fish size distribution and fish abundance estimates obtained with hydroacoustics and gill netting in the open water of a large shallow lake
}

\author{
I. Tátrai ${ }^{*}$, A. Specziár ${ }^{1}$, A. I. György ${ }^{1,2}$, P. Bíró ${ }^{1}$ \\ ${ }^{1}$ Balaton Limnological Research Institute of the Hungarian Academy of Sciences, H-8237 Tihany, Hungary. \\ 2 Pannon University, Department of Limnology, H-8200 Veszprém, Hungary
}

\begin{abstract}
The distribution and overall fish abundance, and biomass of fish populations in the open water of meso-eutrophic Lake Balaton were studied in 2003-2007 using hydroacoustics and gill nets. Gillnet catches revealed that bleak (53-76\%) common bream (8-42 $\%)$, white bream and razor fish (2-18\%) dominated in the open water of the lake. Comparisons of target strength distribution from hydroacoustics and length distribution from the gillnets showed that the fishing gear did not quantitatively catch the smallest and largest size groups of fish. Mean acoustic fish abundance and biomass fluctuated significantly between both basins and years. The biomass of fish populations reflects the trophic gradient along the longitudinal axis of the lake (min-max.: 89-181 kg ha-1) showing a decreasing trend with years. The mean acoustic fish biomass was significantly higher in the eutrophic western basin, compared with mesotrophic eastern and middle ones.
\end{abstract}

Keywords: split beam echo sounding; horizontal beaming, gillnet catches, fish abundance and biomass, shallow lake

\section{Introduction}

Reliable estimates of fish abundance and biomass in lakes are important fundamentals for many purposes. Data on species composition, length distribution of a commercially used fish stock is required for sustainable fisheries management (Ney 1993, Mehner et al. 2003). Among others, quantitative ecological investigations like food web studies may be substantially improved by consistent data on fish biomass (Schulz et al. 2003). In fisheries management severe errors may have been made due to the inaccuracy in stock assessment (Peltonen et al. 1999). Different assessment procedures may generate contradictory estimates (Schnute \& Hilborn 1993, Mason et al. 2005). Conclusions about fish stock dynamics are likely to be more secure if different fish stock evaluation methods are compared, and if they produce sound estimates.

\footnotetext{
* Corresponding author : E-mail : tatrai@tres.blki.hu
}

Recently, hydroacoustics as a precise method for assessment of fish abundance proved a useful fisheries management tool for avoiding some of the selectivity issues encountered with traditional gear types (Kubečka et al. 1998, Knudsen \& Saegrov 2002, Mehner et al. 2003, Gangl \& Whaley 2004). Moreover, the results of a single hydroacoustic survey can be reproduced reliably and split-beam survey systems differing in sound frequency, beam width and shape, pulse length and ping rate can produce comparable biomass estimates (Wanzenböck 2003). However, reliability of hydroacoustic fish density estimates are subject to large variations due to different factors (Malinen \& Tuomaala 2005). One of the most important sources of variations is timing of the survey and the effect of changes in distributional patterns of fishes in the water column.

During the years of 1970-1990, Lake Balaton (Hungary) has been heavily impacted by human activities. High point and non-point sources of nutrient loading have led to eutrophication (Herodek 1986). To accelerate recovery of Lake Balaton, chemical and biological restoration methods have been applied between 19892002 (Jeppesen et al. 2005, Tátrai et al. 2008). A reduc- 
tion in the external and internal Phosphorus loadings along with the removal of cyprinid fish resulted in a significant improvement of the water quality of the lake. Balaton, next to its ecological values, is an internationally important recreational lake. Beside commercial fisheries, more than 100000 sport fishermen visit the lake annually. Direct surveys and catch data suggest that while community structure changed only slightly, fish biomass responded negatively to reduction in nutrient loading in L. Balaton (Bíró 2000).

By this time, information on fish stock of Lake Balaton is based on gillnetting and seining. However, accurate biomass estimates of the pelagic fish species are still lacking. Pelagic fish species, which live in the water column of Lake Balaton, are abundant and dominate by omnivore cyprinids (e.g., common bream, Abramis brama L., bleak, Alburnus alburnus L., razor fish, Pelecus cultratus L., silver carp Hypophthalmichthys molitrix Cuv. et Val., rudd, Scardinius erythrophthalmus L. asp, Aspius aspius L.). Quantitative estimates of pelagic fish species are keys to understanding the capacity of Lake Balaton to support current and future populations of wild and hatchery produced predators. The objective of this study was to determine temporal and spatial distribution of fish during 2003-2007 and to estimate the fish abundance and total fish biomass in the open water of Lake Balaton using hydroacoustics and gillnetting. For comparison between gear types, multimesh gillnets were used to obtain in situ data on relative abundance and length distribution of fish populations. Our aims were : (a) to study the between basin variability of fish abundance and biomass estimates and to determine whether the frequency distribution of single targets from hydroacoustics can reflect the size distribution of fish populations, particularly the occurrence of young fish; and (b) to correlate gillnet data on fish length and abundance per size class with the hydroacoustic data.

\section{Materials and methods}

\section{Study area}

Lake Balaton is situated in the western part of Hungary, in Transdanubia $\left(46^{\circ} 42^{\prime}-47^{\circ} 04^{\prime} \mathrm{N}, 17^{\circ} 15^{\prime}-18^{\circ} 10^{\prime}\right.$ $\mathrm{E}$ at $104.8 \mathrm{~m}$ above sea level). The lake is used for recreational purposes and more than 2 million tourists visit the lake every summer. The total surface area of the lake is $596 \mathrm{~km}^{2}$ and it is the largest calcareous lake in Central Europe (length: $77 \mathrm{~km}$; width: 8 - $16 \mathrm{~km}$ ) (Table 1). Despite its large area, the mean depth is only
Table 1. Hydrological and characteristics of Lake Balaton (after Bíró, 1984, Reskóné-Nagy, 2006).

\begin{tabular}{ll}
\hline Water surface & $59000 \mathrm{ha}$ \\
$\quad$ length & $77 \mathrm{~km}$ \\
$\quad$ width & $8-16 \mathrm{~km}$ \\
Maximum depth & $11.2 \mathrm{~m}$ \\
Mean depth & $3.2 \mathrm{~m}$ \\
Water residence time & $3-8$ years \\
Mean annual water temperature & $12.2^{\circ} \mathrm{C}$ \\
$\mathrm{pH}$ & $8.4-8.7$ \\
Conductivity & $660 \mu \mathrm{S} \mathrm{cm}^{-1}$ \\
Maximum summer chlorophyll-a values \\
$\quad$ eastern basin & $17,6 \mathrm{ug} \mathrm{l}^{-1}$ \\
$\quad$ middle basin & 47.0 \\
western basin & 60.6 \\
\hline
\end{tabular}

$3.2 \mathrm{~m}$ and the mean water residence time is $3-8$ years (Table 1). There are 51 minor inflows, 20 of which are permanent ones. The water is frequently turbid because of sediment resuspension and calcite precipitation. The present trophic state of the lake varies from the meso(eastern and middle basins) to eutrophic (western basin) along the longitudinal axis (Reskóné et al. 2006) and the maximum summer chlorophyll-a concentration does not exceed $75 \mathrm{gg}^{-1}$ (Table 1). The natural shoreline (red grass stands) has been limited to $110 \mathrm{~km}$. The remaining $105 \mathrm{~km}$ of shoreline is artificially protected with stones and/or concrete walls reducing the original spawning sites and nursery areas for fish.

The fish fauna of the lake consists of 30 permanent species of which common bream, razor fish, bleak and the introduced silver carp are the most abundant in biomass (Bíró 1997, Specziár et al. 2000).

\section{Hydroacoustic survey}

Hydroacoustic data in Lake Balaton were collected in June - October 2003-2004, in October 2006 and April-May 2007. For surveys, we have chosen the days when the wind speed was around $1 \mathrm{~m} \mathrm{sec}^{-1}$. Hydroacoustic data were collected during daytime in the morning (between 08.00-10.00 hours), when most of the cyprinid fish populations are dispersed over the water column, thus enabling a high single target resolution. 
Boat speed for all surveys was 1.6-2.1 $\mathrm{m} \mathrm{sec}^{-1}$. Acoustic data were collected with SIMRAD EK 60 split - beam echosounder $\left(120 \mathrm{kHz}\right.$, circular beam shape with $7^{\circ}$ angle at - $3 \mathrm{~dB}$ level, pulse duration $256 \mu \mathrm{s}, 14-16$ pings $\mathrm{s}^{-1}$ ) (Table 2). The echosounder was calibrated each year using a copper calibration sphere following the standard SIMRAD EK60 protocol. The transducer was mounted horizontally on a towed body, which was lowered to a depth of 0.4-0.5 $\mathrm{m}$ on the prow of the boat and tilted $2-3^{\circ}$ downwards. Acoustic data collected during transects were stored on a computer and analysed using SIMRAD Sonar4 (v. 5.8.7) post-processing software (Lindem Data Acquisition; Oslo, Norway).

We conducted horizontal surveys in three basins (eastern, middle and western) along 36 transects (three basins $* 2$ times per year $* 2$ years $* 3$ replicates). (Fig. 1). Length of each transect was between $1.2-1.6 \mathrm{~km}$. Ten layers from 3 to $18 \mathrm{~m}$ (each $1.5 \mathrm{~m}$ thick) were used for analysis of target sizes and densities. Calm conditions enabled us to keep relatively low noise threshold and most of fish sizes down to 0+ fry could be observed during our survey, especially in October. Acoustic abundances were based on targets larger than $-50 \mathrm{~dB}$, corresponding to cyprinids $>4 \mathrm{~cm}$ of total length $\left(\mathrm{L}_{\mathrm{T}}\right)$. Smaller targets were considered noise. The TS distribution of the targets $(3 \mathrm{~dB}$ classes according to SIMRAD software) from each transect was converted into fish total length distribution by the equation for $120 \mathrm{kHz}$ echosounder in horizontal plane and for all body aspect by Love (1977). Frequency distribution of $\mathrm{TS}$, were collated into $3 \mathrm{~dB}$ bins and were used to compare fish length data from gillnets samples. Length of fish was converted into biomass by using our empirical length $\left(\mathrm{L}_{\mathrm{T}}\right)$ weight $(\mathrm{W})$ regression including the four most frequent fish species (common bream, Abramis brama L., $\mathrm{n}=109$; white bream, Blicca bjoerkna L., $\mathrm{n}$ = 89; bleak, Alburnus alburnus L., $\mathrm{n}=166$; and razor fish, Pelecus cultratus L., $\mathrm{n}=121$ ) of the lake (W = $0.0043 \mathrm{~L}_{\mathrm{T}}^{3.369}, \mathrm{n}=485, \mathrm{R}^{2}=0.943$ ). All conversions of the logarithmic TS distribution into fish biomass were based on an unbiased estimate of mean fish weight per $3 \mathrm{~dB}$ group as described in Simmonds \& MacLennan (2005). Average fish density (ind ha-1) and biomass ( $\mathrm{kg}$ $\mathrm{ha}^{-1}$ ) for the basins and the total lake were calculated.

\section{Gillnetting}

In each basin of Lake Balaton, a pair of monofilament multi-mesh gillnets ( $240 \mathrm{~m}$ length in total) were set directly next one another simultaneously with the hydroacoustic survey in the morning in June- October 2003-2004, October 2006 and April-May 2007 (between 08-10 hours) (Fig. 1). Each net had nine different mesh sizes $(11,14,18,24,30,40,50,65$ and $80 \mathrm{~mm})$ and was $120 \mathrm{~m}$ long and $3 \mathrm{~m}$ high. Gillnet panels $11-40 \mathrm{~mm}$ mesh sizes were $10 \mathrm{~m}$ long, while panels $50-80 \mathrm{~mm}$ mesh sizes were $20 \mathrm{~m}$ long. Catches of the $10 \mathrm{~m}$ and $20 \mathrm{~m}$ long panels were handled separately before stand-

Table 2. Echosounder, transducer and analysis parameters used in fish stock estimation in Lake Balaton.

\begin{tabular}{|c|c|}
\hline \multicolumn{2}{|l|}{ Simrad EK 60- split beam echosounder } \\
\hline Operating frequency & $120 \mathrm{kHz}$ \\
\hline Transmission power & $300 \mathrm{~W}$ \\
\hline \multicolumn{2}{|l|}{ Simrad ES 120 - 7C-circular beam transducer } \\
\hline Nominal $3 \mathrm{~dB}$ beam angle & $7^{\circ}$ \\
\hline Face diameter & $10 \mathrm{~cm}$ \\
\hline \multicolumn{2}{|l|}{ Transceiver } \\
\hline Pulse duration & $0.256 \mathrm{msec}$ \\
\hline Frequency bandwidth & $12 \mathrm{kHz}$ \\
\hline \multicolumn{2}{|l|}{ Single echo detector } \\
\hline Min. returned pulse width & 0.6 fold transmitted pulse duration \\
\hline Max. returned pulse width & 1.2 fold transmitted pulse duration \\
\hline Max. phase deviation & 10 phase steps \\
\hline Max. beam compensation & $3 \mathrm{~dB}$ \\
\hline TS threshold for $40 \log \mathrm{R}$ TVG for data collection & $-60 \mathrm{~dB}$ \\
\hline TS threshold for $40 \log \mathrm{R}$ TVG for post processing & $-50 \mathrm{~dB}$ \\
\hline
\end{tabular}


ardization for fishing effort. All fish were identified to species level and total length $\left(\mathrm{L}_{\mathrm{T}}\right)$ and mass measured in the laboratory. Gillnet catches were converted to Catch per Unit Effort (CPUE, ind $\mathrm{h}^{-1}$ standard net ${ }^{-1}$ and $\mathrm{g} \mathrm{h}^{-1}$ standard net ${ }^{-1}$ ) following a gear standardisation for panel size (standard net is a $90 \mathrm{~m}$ long net composed of nine panels of equal $10 \mathrm{~m}$ length) and fishing time (standard setting time is a 1 hour) with PASGEAR (Kolding 1997). However, data were not corrected for gillnet selectivity.

\section{Data analysis}

Analysis of Variance (ANOVA) was used to test the null hypothesis that no differences existed in neither acoustic fish abundance nor in acoustic biomass among basins. Prior to ANOVA testing, the dependent variable was $\log _{10}$ transformed to minimize heteroscedasticity. The means of estimated total abundance and biomass in each basin were compared using post-hoc analyses by Tukey's multiple tests. Means total fish abundance and biomass for the whole lake between years was compared using paired t-tests.

Correlation between the standardized CPUE abundance and biomass derived from nets and abundance and biomass calculated from hydroacoustics in three basins of the lake for the years 2003-2004 was tested using pairwise correlation. Given that the gillnets used in our study did not include panels $<11 \mathrm{~mm}$ mesh sizes which would be required for the catch of the smallest size class of fish recorded by the echosounder, the < $6 \mathrm{~cm}$ size class was excluded from comparative analysis. Analyses were conducted using SYSTAT (version 11.0).

\section{Results}

\section{Length frequency distribution}

We have compared the relative proportions of fish lengths within the corresponding $3 \mathrm{~dB}$ classes of TS with the length distribution of fish from gill nets in Lake Balaton in 2003-2007. It has turned out that the hydroacoustic data fully matched the in situ situation in 2003-2004 (Fig. 2). However, in 2006 and 2007 sufficient differences were observed in the length proportion between hydroacoustics and gill net catches. The most obvious deviation was that in the gillnets, almost no small and large fish were caught whereas these individuals were counted by echosounder. The peak in distribution coincided only for fish about $12-14 \mathrm{~cm}$ $\mathrm{L}_{\mathrm{T}}$. In 2003 and 2006, the highest proportion (30\% of all echoes) was observed for the fish group of about 12 $\mathrm{cm} \mathrm{L}_{\mathrm{T}}$. At the same time in 2004 and 2007 the highest proportion was found for the fish groups of about 4 and $12-13 \mathrm{~cm} \mathrm{~L}_{\mathrm{T}}$.

\section{Acoustic fish abundance and biomass}

Mean acoustic fish abundance for the whole lake fluctuated significantly both between years (ANOVA, $\left.\mathrm{F}_{3,104}=74.345, \mathrm{P}=0.000\right)$ and basins (ANOVA, $\mathrm{F}_{11,96}=$ $49.115 \mathrm{P}=0.000$ ) in 2003-2004 and 2006-2007 (Table 3 ). Post-hoc analyses by Tukey's multiple comparisons indicated that the mean acoustic fish abundance in Lake Balaton was significantly higher in 2003 as compare with 2004 and 2006 years ( $p<0.0001$ for both years). However, mean fish abundance did not differ significantly between 2003 and 2007 (post-hoc analyses by Tukey's multiple comparisons, p> 0.05) (Fig. 3a). Mean acoustic fish abundance collected during 2003 varied with basins (ANOVA, $\mathrm{F}_{2,33}=16.617, \mathrm{P}=0.000$ ). Post-hoc analyses by Tukey's multiple comparisons indicated that the mean acoustic fish abundance in 2003 was significantly higher in the eutrophic western basin as compare with the eastern $(\mathrm{p}<0.001)$ and middle ones $((\mathrm{p}<0.0001)$. However, no difference existed in fish abundance between eastern and middle basins ( $p>0.270$ ). In 2004, the variance in fish abundance continued with basins (ANOVA, $\mathrm{F}_{2.33}=20.379, \mathrm{P}=$ 0.000). Tukey's HSD post hoc tests indicated that the fish abundance associated with basins was higher in the mesotrophic eastern basin than in both meso trophic middle $(p<0.001)$ and eutrophic basins $(p<0.05)$. Fish abundance was similar in the middle and western basins ( $p>0.05$ ). Different pattern of acoustic fish abundance was observed in the lake in 2006, as the fish did not differ across the basins (ANOVA, $\mathrm{F}_{2,15}=2.103, \mathrm{P}=$ 0.157). Mean acoustic fish abundance in 2007 varied again with basins ((ANOVA, $\mathrm{F}_{2,15}=6.201, \mathrm{P}=0.011$ ) and was the highest in the western basin significantly greater than in the eastern and middle basins (post-hoc analyses by Tukey's multiple comparisons, $\mathrm{p}<0.05$ for both).

Mean acoustic fish biomass for the whole lake collected between 2003-2004 and 2006-2007 varied with both the years (ANOVA, $\mathrm{F}_{3,104}=21.881, \mathrm{P}=0.000$ ) and basins (ANOVA, $\mathrm{F}_{11,96} \stackrel{2}{=} 42.699, \mathrm{P}=0.000$ ) (Fig. $3 b)$. Post-hoc analyses by Tukey's multiple comparisons indicated that the mean acoustic fish biomass in L. Balaton was significantly higher in 2003 as compare with 2004, 2006 and 2007 years ( $<<0.01$ for all years). 


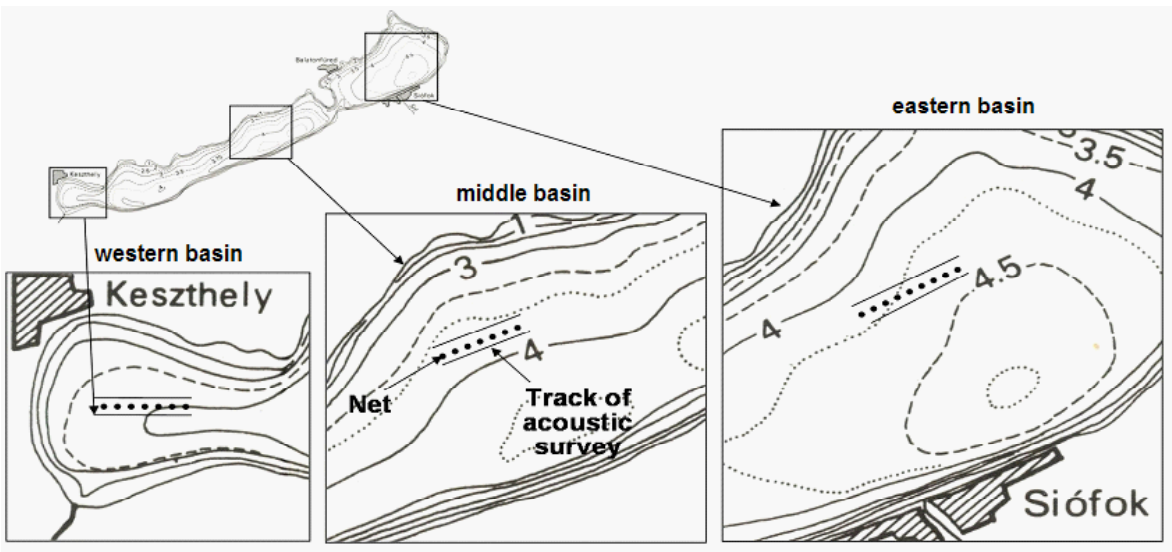

Fig. 1. Contour map with isolines and transects sampled with the echosounder and gillnets in Lake Balaton.
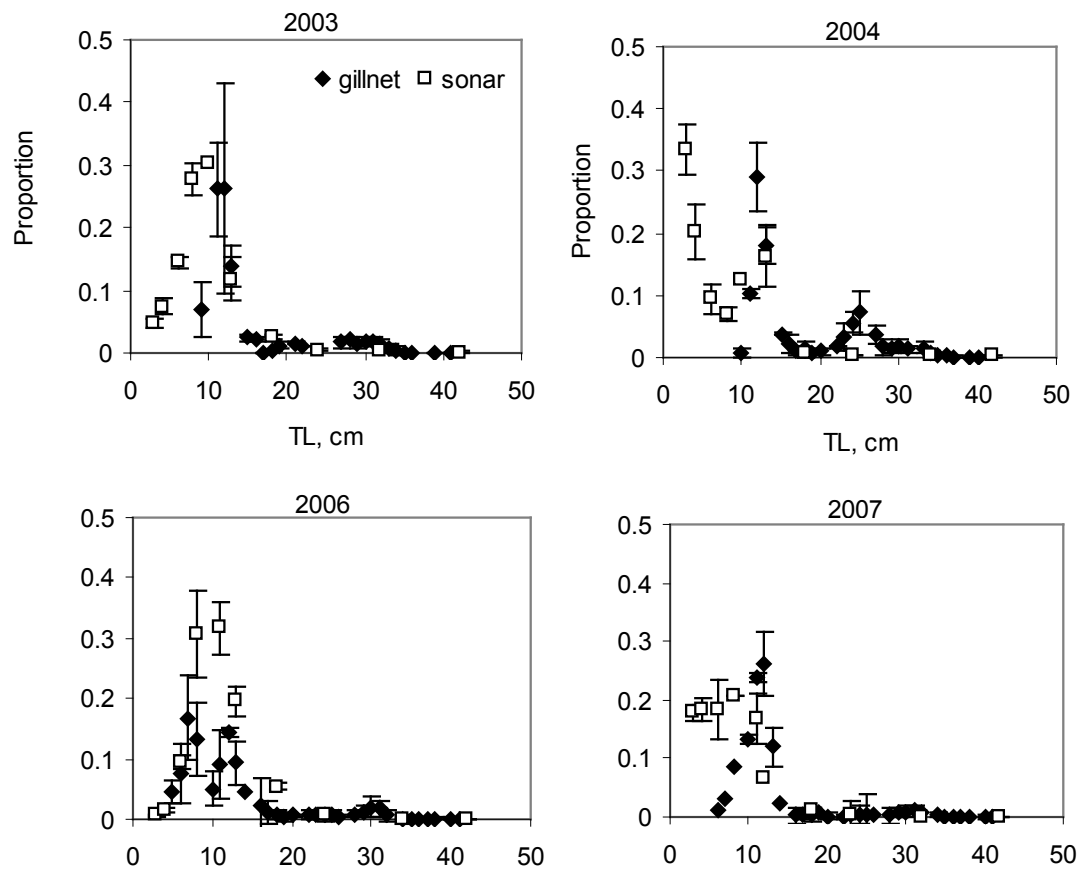

Fig. 2. Size distribution of fish from gill net catches and hydroacoustics in Lake Balaton in 2003-2004 and 2006-2007. 
Table 3. Fish density (ind ha $\left.{ }^{-1}\right)$ and fish biomass $\left(\mathrm{kg} \mathrm{ha}^{-1}\right)$ in the three basins of the open water of Lake Balaton obtained by horizontal $120 \mathrm{kHz}$ split beam echosounding in 2003-2007. Mean values (95\% CI in brackets) for the basins and for the total lake are given.

\begin{tabular}{ccccccccc}
\hline Years & \multicolumn{3}{c}{$\begin{array}{c}\text { Fish abundance } \\
\left(\text { ind ha }^{-1}\right)\end{array}$} & & & $\begin{array}{c}\text { Areal biomass } \\
\left(\mathrm{kg} \mathrm{ha}^{-1}\right)\end{array}$ \\
\cline { 2 - 8 } & eastern basin & middle basin & western basin & total lake & eastern basin & middle basin & western basin & total lake \\
\hline 2003 & $6180.4(478.1)$ & $5512.8(549.8)$ & $7602.5(627.1)$ & $6432.2(386.0)$ & $111.2(9.9)$ & $114.9(8.7)$ & $315.8(23.8)$ & $180.6(33.7)$ \\
2004 & $6710.4(522.1)$ & $4224.6(314.3)$ & $3586.6(319.5)$ & $4840.4(610.4)$ & $113.6(14.3)$ & $73.0(9.5)$ & $155.9(15.7)$ & $114.2(17.2)$ \\
2006 & $1839.7(171.4)$ & $1934.7(208.9)$ & $3501.2(369.5)$ & $2425.1(436.8)$ & $33.5(2.4)$ & $137.3(14.0)$ & $192.7(22.1)$ & $120.9(27.4)$ \\
2007 & $6660.3(425.7)$ & $3489.2(204.4)$ & $8786.2(561.2)$ & $6311.9(855.5)$ & $79.2(5.4)$ & $76.3(6.2)$ & $112.9(8.2)$ & $89.4(9.1)$ \\
\hline
\end{tabular}
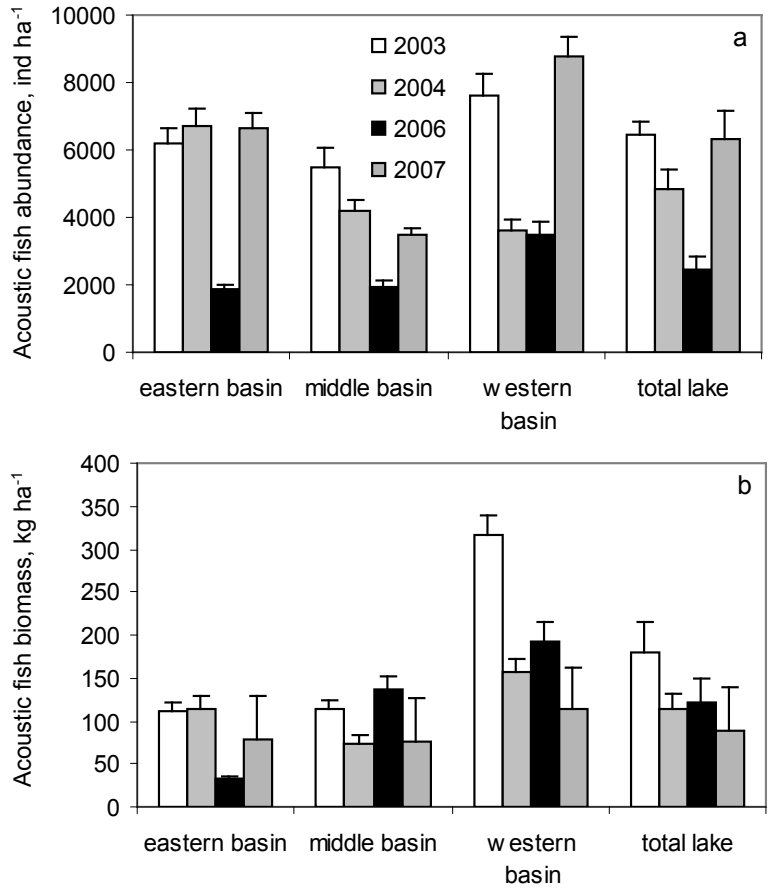

Fig. 3. Calculated mean fish abundance (a) and biomass (b) of Lake Balaton and its eastern middle and western basins (mean $\pm 95 \%$ CI)

Nevertheless, the mean acoustic fish biomass did not differ significantly $(\mathrm{p}<0.05)$ between the years 2004 and 2007. Overall, there was a decreasing trend in the fish biomass in 2003-2007. Mean acoustic fish biomass collected during 2003 varied with basins (ANOVA, $\left.\mathrm{F}_{2,33}=59.489, \mathrm{P}=0.000\right)$. Post-hoc analyses by Tukey's multiple comparisons indicated that the mean acoustic fish biomass in 2003 was significantly higher in the eutrophic western basin as compare with the eastern ( $\mathrm{p}$ $<0.001$ ) and middle ones ( $<$ 0.0001). In 2004, the variance in fish biomass continued with basins, but with lower amplitudes (ANOVA, $\mathrm{F}_{2,33}=6.113, \mathrm{P}=0.006$ ). Tukey's HSD post hoc tests indicated that the mean fish biomass was associated with the trophic state of the basins and proved to be significantly higher in the eutrophic western basin as compared with mesotrophic eastern $(\mathrm{p}<0.01)$ and middle $(\mathrm{p}<0.05)$ basins. Similar trend in variance in the mean acoustic fish biomass was observed in 2006 and 2007 (ANOVA, $\mathrm{F}_{2.15}=275.660$, $\mathrm{P}=0.000$ and $\mathrm{F}_{2,15}=6.414, \mathrm{P}=0.010$, respectively). Tukey's HSD post hoc tests indicated that the mean fish biomass was associated with the trophic state of the basins ( $\mathrm{p}$-values varied between $\mathrm{p}<0.001-\mathrm{p}<0.05$ ).

\section{Gillnet catches}

During the 36 fishing trials, 35567 fish consisting of 11 species were caught by gill netting. Gillnet catches in all years were clearly dominated by bleak, Alburnus alburnus L., (53-76 \%) in all basins. Other abundant species were bream, Abramis brama L., (8-42\%) white bream, Blicca bjoerkna L., and razor fish, Pelecus cultratus L. (2-18\%). CPUE abundance values showed great variations between years and basins (ranging from 61 to 173 ind $^{-1}$ standard net $^{-1}$ ) and were by $55-63 \%$ higher in the western basins than in the middle and eastern ones. Most of the fish captured by gillnets were in size classes 10-12 cm total length $\left(\mathrm{L}_{\mathrm{T}}\right)$ and $21-26 \mathrm{~cm} \mathrm{~L}_{\mathrm{T}}$ $\left(\right.$ CPUE $=32-173$ ind $^{-1}$ standard net $\left.^{-1}\right)($ Figure $4 a)$.

Total CPUE biomass of fish varied between 1320 and $8973 \mathrm{~g} \mathrm{~h}^{-1}$ standard net ${ }^{-1}$ during 2003-2004 and 2006-2007 (Figure 4b). Mean total CPUE biomass in the eutrophic western basin was by $10-35 \%$ higher as 

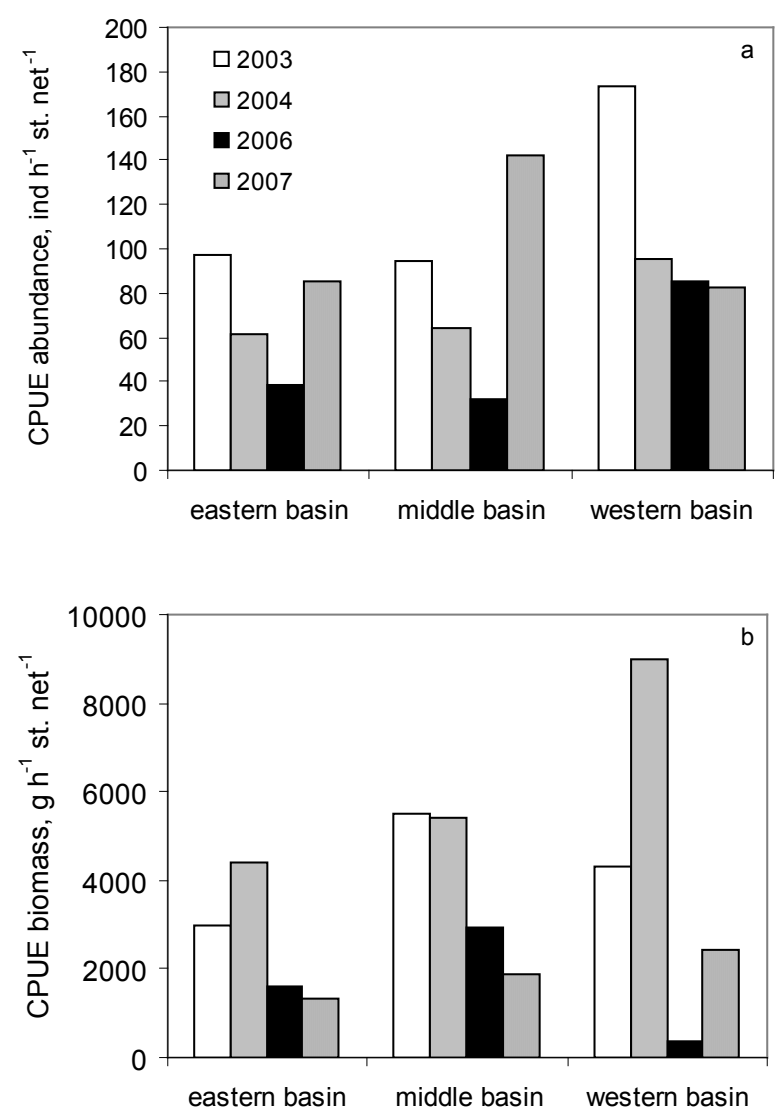

Fig. 4. Standardized gillnet CPUE abundance (a) and CPUE biomass of captured fish in the three basins (eastern, middle and western) of Lake Balaton estimated in 2003-2007

compared with meso trophic basins. The composition of gillnet catches differed between years. CPUE biomass was dominated by razor fish in $2003(17-44 \%)$, by bream in $2004(46-78 \%)$ and $2006(19-49 \%$ and by bleak in 2007 (29-55\%). Other species were bleak (8-38\%), white bream (0-22\%), common carp (0-19 $\%)$ and gibel (3-4\%).

\section{Comparison between gillnet catches and acoustics}

CPUE abundance seems to be a useful for predicting fish density. Pairwise comparison between gillnet caches of fish of $\mathrm{L}_{\mathrm{T}}>6 \mathrm{~cm}$ and acoustic fish abundance for 2003-2004 and 2006-2007 years yielded positive
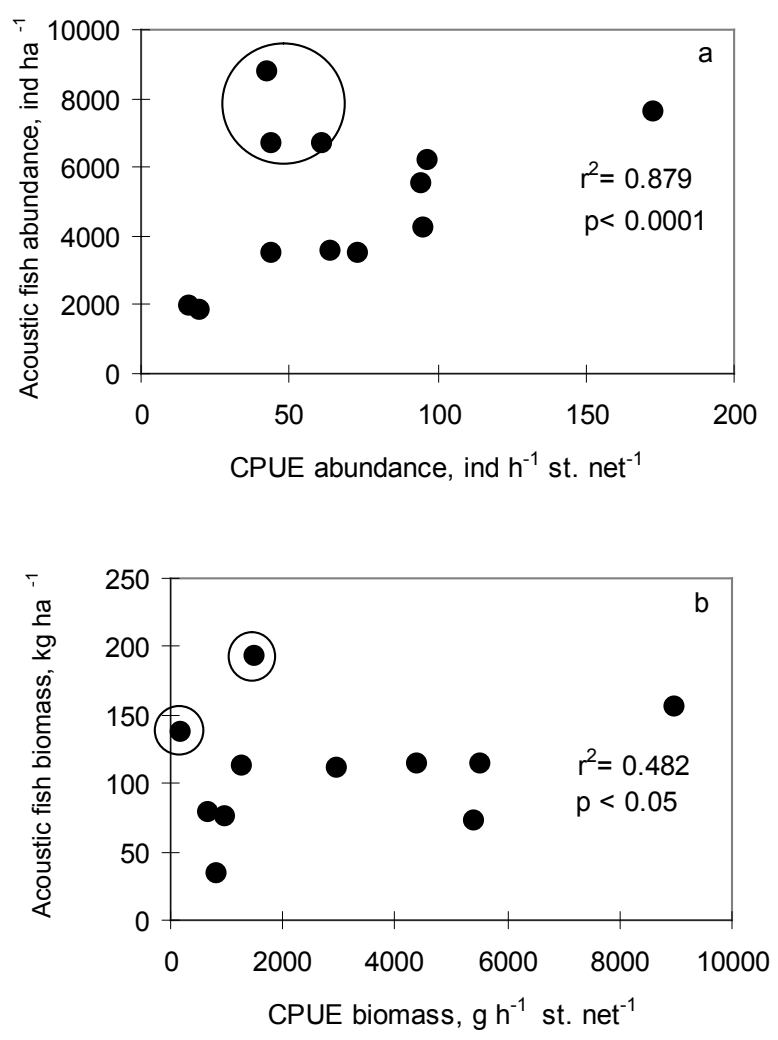

Fig. 5. Pairwise correlation between the corrected CPUE abundance of fish caught by gillnetting and fish abundance calculated from hydroacoustics (a) and CPUE biomass and acoustic fish biomass (b) for size groups $>6 \mathrm{~cm} \mathrm{~L}_{\mathrm{T}}$ for the 2003-2007 years in Lake Balaton. (The circles represent the outliers)

and highly significant correlation $\left(r^{2}=0.897, t=7.790\right.$, $\mathrm{P}=0.000$ ) (Figure 5a). Three cases were outliers and not included in the regression. There is no doubt that a significant amount of the variation in acoustic fish abundance is explained by CPUE abundance (ANOVA, $\mathrm{F}_{17}$ $=60.689, \mathrm{P}=0.000)$. Likewise to CPUE abundance, CPUE biomass in gillnets and hydroacoustic fish biomass were correlated too over the samplings done in 2003-2004 and 2006-2007 $\left(\mathrm{r}^{2}=0.482, \mathrm{t}=2.553, \mathrm{P}=\right.$ 0.038 ) (Figure $5 \mathrm{~b}$ ). Two cases were outliers and not included in the regression. A significant amount of the variation in acoustic fish biomass is explained by CPUE biomass (ANOVA, $\mathrm{F}_{1,7}=6.519, \mathrm{P}=0.038$ ). 


\section{Discussion}

Our study has shown that hydroacoustics provide a useful means for estimating fish size frequency distribution, abundance and biomass in large shallow lakes (Simmonds \& MacLennan 2005, Boswell et al. 2007). It has become evident that it is possible to detect fish in large shallow lakes ( $>2 \mathrm{~m}$ ) using horizontally deployed split beam hydroacoustics in a mobile survey. Hydroacoustics is a unique fish sampling technique and offer opportunity for the direct estimation of acoustic fish abundance, size frequency distribution and acoustic fish biomass. Computation of biomass based on acoustic survey requires an assumption that is an overall fish TS- $\mathrm{L}_{\mathrm{T}}$ relationship has to be supposed, especially for such a mixed fish species assemblage what we are facing to in Lake Balaton. Although the TS- $\mathrm{L}_{\mathrm{T}}$ relationship proposed by Frouzova et al. (2005) exists for European freshwater fishes (cyprinids, salmonids and percids), but only from $7.2 \mathrm{~cm} \mathrm{~L}_{\mathrm{T}}$. That was the main reason why we adopted the Love's (1977) equation for all body aspect to get acoustic information for fish in L. Balaton. Due to the good match of the data for the medium-sized fish, it seems possible that the formula by Love (1977) can be used to convert TS into fish length for horizontal echosoundings in shallow lakes dominated by bleak and bream. The largest source of variation for the horizontal survey is the effect of fish orientation relative to the transducer and then the translated error on biomass estimates. The effects of fish orientation on TS have been well documented (Simmonds \& MacLennan 2005). The potential influence of fish orientation may occasionally be considerable (Boswell et al. 2007) in the open water of L. Balaton in a similar way considering the schooling behaviour of bleak as one of the dominant scaterrer. Direct observation of such a schooling fish is needed to explain their input to the general scattering on a species-specific level.

Based on gillnet data, the majority of acoustic backscattering data collected during all years may be attributable to bleak, common- and white breams and razor fish, the most numerous species in all basins of the lake. The comparison of relative proportions of fish lengths between gillnet catches and acoustics in the open parts of Lake Balaton showed similarities in ranges across basins, although differences were apparent between years and maybe due to difference in the distribution of schooling YOY fish. Deviations in relative proportions of fish lengths were pronounced for the small and large fish. The $0+$ fish, which are $<7 \mathrm{~cm}$ in total length by the autumn (Specziár et al. 1997) were not caught by the gillnets. As regards the selectivity of gillnets for larger fish of $>30 \mathrm{~L}_{\mathrm{T}}$, their density was too low to guarantee that these fish recorded by acoustics were caught by relatively short gillnets. This contradicts to the Boswell's et al. (2007) observations that is the larger fish caught by gillnets were underrepresented in the acoustic records. The potential explanation given is that larger fish captured were bottom oriented. In our study, the larger benthivorous species (common- and white breams) were well sampled by acoustics being by about $20 \mathrm{~cm}$ apart from the sediments. According to Kubečka et al. (1997) targets being more than $18 \mathrm{~cm}$ from the bottom with no respects to their orientation are well sampled.

The most obvious deviation between gillnet catches and data from hydroacoustics was found in the younger fish populations. Consequently if $>+1$ age groups of fish were considered, acoustic fish abundance and CPUE numbers from gillnets were correlated over six sampling dates during 2003-2007. The selectivity of the passively catching gillnets had stronger influence on the weak match between acoustic and gillnet data regarding the fish biomass. A reasonably good correlation between CPUE abundance and hydroacoustic abundance could be achieved for larger vendace (Coregonus albula L.), in Lake Stechlin (Mehner \& Schulz 2002), sea fish (sprat, Sprattus sprattus, L., and herring, Clupea harengus, L.) (Hansson \& Rudstam 1995) and for large (> 20 $\mathrm{cm}$ ) pelagic Arctic charr (Salvelinus alphinus L.) and brown trout (Salmo trutta L.) in Windermere (Elliott \& Fletcher 2001).

Hydroacoustic fish density estimates are subject to large variations due to the variety of factors. One of the most important sources of variation is the timing of the survey. According to a great majority of studies, nighttimes is more suitable for assessment than other periods (Appenzeller \& Leggett 1992, Swierzowski 2003, Kahilainen et al. 2004, Malinen \& Tuomaala 2005). During the night, fish are typically dispersed in midwater of deep lakes making in situ target strength measurements possible and eliminating the effect of acoustic shadowing (Appenzeller \& Leggett 1992). Unfortunately, no information is available on fish diel pattern in open water area of Lake Balaton. However, Draštík \& Kubečka (2005) during a horizontal survey observed a random vertical distribution of fish in about $2 \mathrm{~m}$ deepwater layer in L. Balaton nighttimes. This assumption was corroborated by the repeatability of our density estimates in all basins. Diurnal patterns of fish stock estimates were studied in gillnet and in the littoral in the eastern basin (Specziár 2001). These results showed a significant diel pattern in both the CPUE and the catch 
composition. In general, the total CPUE increased markedly at sunset, stayed high during the night and dropped drastically with the sunrise. However, during the day the CPUE was quite stable. This pattern was similar in all sampling dates. Hydroacoustic data in Lake Balaton were collected in open water during daytime only from the morning assuming that migrations did not take place during those hours and most of the cyprinid fish populations are dispersed over the water column enabling thus a high single target resolution.

Fish stock of Lake Balaton had been studied for many decades using data obtained by conventional gillnetting and using fishery statistics (Bíró 1984, 1997, 2000, Specziár 2001). Obtaining reliable estimates on acoustic fish abundance and biomass in this large shallow lake seems to be a difficult task. However, as pointed out by Kubečka, Frouzová \& Zdenek (1997) horizontal application of narrow beamed scientific sonar appears to be one promising way of covering extensive areas of the lake for obtaining quantitative data on fish stock. Following Kubečka et al. (1997) survey along the northern shore of the lake close to the littoral, our results represent a significant first step for quantifying fish abundance and biomass using hydroacoustics in the open water of Lake Balaton. Mean acoustic fish abundance and biomass fluctuated significantly between both basins and years. The biomass of fish populations reflects the trophic gradient along the longitudinal axis of the lake (min-max.: $34-316 \mathrm{~kg} \mathrm{ha}^{-1}$ ) showing a decreasing trend with years. Our hydroacoustic estimates of fish abundance and biomass in the open water of L. Balaton between 2003-2007 are comparable with those obtained by Kubecka et al. (1997) in 1997 (min-max.: 83-251 $\left.\mathrm{kg} \mathrm{ha}^{-1}\right)$. In fisheries management the accuracy in stock assessment is a key question (Peltonen et al. 1999). In many cases, different stock assessment procedures may result in divers and some times contradictory estimates. The discrepancy can be substantial and varying within extremely wide range (factor: 2-25) (Schnute \& Hilborn 1993, Mason et al. 2005). For L. Balaton, mean lake-wide biomass of fish was $180.6 \mathrm{~kg} \mathrm{ha}^{-1}$ in 2003 and it dropped to $89 \mathrm{~kg} \mathrm{ha}^{-1}$ by 2007. Difference in acoustic fish biomass between basins of different trophy is two-three times lower comparing to the values assessed from fishery yields in the 1980s (Bíró 2000). Analyses of commercial catches reveal strong fluctuations and a decrease in the number and biomass of native fish species between 1980-1995.

Increased efforts in acoustics to quantify fish assemblages in different habitats of L. Balaton may provide insight into the fish stock size and its dynamics. Moreover, a more rigorous gillnetting is necessary to determine the species composition for calculating species- specific biomass estimates from acoustics and for establishing TS-total length relationship. Finally, the comparison of hydroacoustic estimates of abundance and biomass to gillnet estimates should be continued to develop a more reliable model to be applied in gillnet determined fish stock estimate.

\section{Acknowledgements}

We are grateful to Kevin M, Boswell for reading and valuable comments made on an earlier version of this manuscript. We thank to G. Dobos for his assistance in the field. This study was supported primarily by the NKFP-project (National Research and Development Project \# NKFP-3B/0014/2002) and partly by the Hungarian National Science Foundation (research projects: OTKA T 048758 and $\mathrm{T}$ 046222).

\section{References}

Appenzeller A.R. \& Leggett W.C. 1992.- Bias in hydroacoustic estimates of fish abundance due to acoustic shadowing: Evidence from day-night surveys of vertically migrating fish. Can. J. Fish. Aquat. Sci., 49, 2179-2189.

Bíró P. 1984.- Lake Balaton: a shallow Pannonian water in the Carpathian basin. Pages 231-245 in Lakes and Reservoirs. Taub F.B. (ed.). Elsevier, Amsterdam.

Bíró P. 1997.- Temporal variation in Lake Balaton and its fish populations. Ecol. Freshwat. Fish, 6, 196-216.

Bíró P. 2000.- Long-term changes in Lake Balaton and its fish populations. Adv. Ecol. Res., 31, 599-613.

Boswell K.M., Wilson M.P. \& Wilson C.A. 2007.- Hydroacoustics as a tool for

assessing fish biomass and size distribution associated with discrete shallow water estuarine habitats in Louisiana. Estuaries and Coasts, 30, 1-11.

Draštík V. \& Kubečka J. 2005.- Fish avoidance of acoustic survey boat in shallow waters. Fisheries Res., 72, 219-228

Elliott J.M. \& Fletcher J.M. 2001.- A comparison of three methods assessing the abundance of Arctic charr, Salvelinus alpinus, in Windermere (northwest England). Fisheries Res., 53, 39-46.

Frouzova J., Kubečka J., Balk H. \& Frouz J. 2005.- Target strength of some European fish species and its dependence on fish body parameters. Fisheries Res., 75, 86-96.

Gangl R.S. \& Whaley R.A. 2004.- Comparison of fish density estimates from repeated hydroacoustic surveys on two Wyoming waters. N. Am. J. Fish. Man., 24, 1279-1287.

Hansson S. \& Rudstam L.G. 1995.- Gillnet catches as an estimate of fish abundance: a comparison between vertical gillnet catches and hydroacoustic abundances of Baltic Sea herring (Clupea harengus) and spratt (Sprattus sparattus). Can. J. Fish. Aquat. Sci., 52, 75-83.

Herodek S. 1986.- Phytoplankton changes during eutrophication and $\mathrm{P}$ and $\mathrm{N}$ metabolism. Pages 183-204 in Modelling and Managing Shallow Lake Eutrophication. Somylódy L. \& van Straten G. (eds). Springer-Verlag, Berlin.

Jeppesen E., Søndergaard M., Jensen J.P., Havens K., Anneville O., Carvalho L., Coveney M.F., Deneke R., Dokulil M., Foy B., Gerdeaux D., Hampton S.E., Kangur K., Köhler J., Körner S., Lammens E., Lauridsen T.L., Manca M., Miracle R., Moss B., Nõges 
P., Persson G., Phillips G., Portielje R., Romo S., Schelske C.L., Straile D., Tátrai I., Willén E. \& Winder M. 2005.- Lake responses to reduced nutrient loading - an analysis of contemporary data from 35 European and North American long term studies. Freshwater Biol., 50, 1747-1771.

Kahilainen K., Malinen T., Tuomaala A. \& Lehtonen H. 2004.- Diel and seasonal habitat and food segregation of three sympatric Coregonus lavaretus forms in a subarctic lake. J. Fish Biol., 64, 418-434.

Knudsen F.R. \& Saegrov H. 2002.- Benefits from horizontal beaming during acoustic survey: application to three Norwegian lakes. Fisheries Res., 56, 205-211.

Kolding J. 1997.- PASGEAR- A Database Package for Environmental Fishery Data from Passive gears. University of Bergen, Bergen, $52 \mathrm{p}$.

Kubečka J., Frouzová J. \& Zdenek P. 1997.- Hydroacoustic assessment of the fish stock in Lake Balaton. Scientific Report, Hydrobiological Institute, Česke Budejovice, 33p.

Kubečka J., Seda J., Duncan A., Matena J., Ketelaars H.A.M. \& Visser P. 1998.- Composition and biomass of the fish stocks in various European reservoirs and ecological consequences. Int. Rev. Hydrobiol., 83, 559-568.

Love R.H. 1977.- Target strength of an individual fish at any aspect. J. Acoust. Soc. Am., 62, 1397-1403.

Malinen T. \& Tuomaala A. 2005.- Comparison of day and night survey in hydroacoustic assessment of smelt (Osmerus eperlanus) density in Lake Hiidenvesi. Archiv Hydrobiol., 59, 161-172.

Mason D.M., Johnson T.B., Harvey C.J., Kitchell J.F., Schram S.T., Bronte C.R., Hoff M.H., Lozano S.J., Trebitz A.S., Schreiner D.R., Lamon E.C. \& Hrabik T. 2005.- Hydroacoustic estimates of abundance and spatial distribution of pelagic prey fishes in western Lake Superior. J. Great Lakes Res., 31, 426-438.

Mehner T. \& Schulz M. 2002.- Monthly variability of hydroacoustic fish stock estimates in a deep lake and its correlation to gillnet catches. J. Fish Biol., 61, 1109-1121.

Mehner T., Gassner H., Schulz M. \& Wanzenböck J. 2003.- Comparative fish stock estimates in Lake Stechlin by parallel split-beam echosounding with $120 \mathrm{kHz}$. Archiv Hydrobiol., 58, 227-236.
Ney J.J. 1993.- Bioenergetics modelling today: growing pains on the cutting edge. Trans. Am. Fish. Soc., 122, 736-748.

Peltonen H., Ruuhijärvi J., Malinen T. \& Horpilla J. 1999.- Estimation of roach (Rutilus rutilus (L.)) and smelt (Osmerus eperlanus (L.)) stocks with virtual population analysis, hydroacoustics and gillnet CPUE. Fisheries Res., 44, 25-36.

Reskóné N., A. Alföldi M., Kiss G., Balogi ZS., Tóth M.E, \& Borsodi A. 2006.- The quality of sediment of Lake Balaton and characteristics of its microbial communities. Hidrol. Köz., 86, 155-158. (Hun., En. sum)

Schnute J.T. \& Hilborn R. 1993.- Analysis of contradictory data sources in fish stock assessment. Can. J. Fish. Aquat. Sci., 50, 1916-1923.

Schulz M., Kasprzak P., Anwand K. \& Mehner T. 2003.- Diet and composition and food preference of vendace (Coregonus albula L.) in response to seasonal zooplankton succession in Lake Stechlin. Archiv Hydrobiol., 58, 215-226.

Simmonds E.J. \& MacLennan, D.N. 2005.- Fisheries Acoustics: Theory and Practice, $2^{\text {nd }}$ edition. Blackwell Science, Oxford, U. K., 437 p.

Specziár A. 2001.- Impacts of the activity of fish on the results of gillnet samplings: diurnal and seasonal changes of the CPUE in Lake Balaton. Hidrol. Közl., 5-6, 459-461. (Hun., En. sum)

Specziár, A., Tölg, L., \& Bíró, P. 2000.- Investigation of Lake Balaton's fish fauna. Halászatfejlesztés, 24, 115-125. (Hun., En. sum.)

Specziár A., Tölg L. \& Bíró P. 1997.-Feeding strategy and growth of cyprinids in the littoral zone of Lake Balaton. J. Fish Biol., 51, $1109-1124$.

Swierzowski A. 2003.- The variability of distribution and density of pelagic fishes in the Roznowski dam reservoir. Arch. Polish Fish., 11, 245-263.

Tátrai, I., Istvánovics, V., Tóth L.G., \& Kóbor, I. 2008.- Management measures and long-term water quality changes in Lake Balaton (Hungary). FAL, 172, 1-11.

Wanzenböck J., Mehner T., Schulz M., Gassner H. \& Winfield I.J. 2003.- Quality assurance of hydroacoustic surveys: the repeatability of fish abundance and biomass estimates in lakes within and between hydroacoustic systems. ICES J. Mar. Sci., 60, 486-492. 